\title{
Design wind loads including torsion for rectangular buildings with horizontal aspect ratio of 1.6
}

\author{
Mohamed Elsharawy, S.M.ASCE${ }^{1}$; Khaled Galal, M.ASCE ${ }^{2}$; Ted Stathopoulos, F.ASCE ${ }^{3}$
}

\begin{abstract}
Limited information is available regarding wind-induced torsional loads on buildings. This paper presents results of tests carried out in a boundary layer wind tunnel using building models with the same plan dimensions (aspect ratio of 1.6) and located in a simulated open terrain exposure for different wind directions. Synchronized wind pressure measurements allowed estimating instantaneous base shear forces and torsional moments on the tested rigid building models. Results were normalized and presented in terms of shear and torsional coefficients for two load cases, namely; maximum torsion and corresponding shear, and maximum shear and corresponding torsion. Comparison of the wind tunnel test results with current torsion- and shear-related provisions in the American Standard (ASCE 7) demonstrates good agreement for low-rise buildings but differences for medium-rise buildings.
\end{abstract}

${ }^{1} \mathrm{Ph} . \mathrm{D}$. Candidate, Dept. of Building, Civil and Environmental Engineering, Centre for Building Studies, Concordia University, Montréal, Québec, Canada H3G 1M8 (corresponding author).

${ }^{2}$ Associate Professor, Dept. of Building, Civil and Environmental Engineering, Concordia University, Montréal, Québec, Canada H3G 1M8.

${ }^{3}$ Professor, Dept. of Building, Civil and Environmental Engineering, Centre for Building Studies, Concordia University, Montréal, Québec, Canada H3G 1M8. 


\section{INTRODUCTION}

There has been a confusion regarding wind-induced torsion on low- or medium-rise buildings due to the different provisions available in current Codes and Standards. For instance, ASCE 7 (2010) introduces two load cases in the envelope method to estimate torsion, namely; maximum torsion with corresponding shear and maximum shear with corresponding torsion. NBCC (2010) specifies only one load case in the static method assigned for low-rise buildings to evaluate maximum shear as well as maximum torsion. Similar to ASCE 7 (2010), the European code (EN 1991-1-4 (2005)) introduces two load cases to evaluate the design shear and torsional loads but for buildings with all heights. When these provisions were compared by Elsharawy et al. (2012) for three low-rise buildings with different aspect ratios $(\mathrm{L} / \mathrm{B}=1,2,3)$, significant differences were found in evaluating design wind loads - see Figure 1.

Wind-induced torsion provisions in the three codes/standards are also different for medium-rise buildings. ASCE 7 (2010) requires introducing $75 \%$ of the full wind load with eccentricity of $15 \%$ of the facing building horizontal dimension for evaluating maximum torsion. On the other hand, NBCC (2010) requires for design of medium-rise buildings to apply $50 \%$ of the full wind load on half of the along wind wall in order to predict the maximum torsion. Non-uniform wind loads were simulated by applying triangular loading in the EN 1991-1-4 (2005). The non-uniform wind loads applied for torsion, in EN 1991-1-4 (2005), allow for torsional moment equivalent to applying the full design wind load with $6 \%$ eccentricity.

Notwithstanding these differences among the mentioned wind load provisions, other codes/standards neglect torsion in the design of low- and medium-rise buildings. For instance, the Australian standard (AS/NZS 1170.2-2011) does not require wind-induced torsion to be considered for the design of buildings with heights lower than $70 \mathrm{~m}$. For taller buildings, torsion shall be applied based on eccentricity of $20 \%$ of building width with respect to the center of geometry of the building on the along-wind loading. 
Very limited information is available in the literature regarding wind-induced torsion on low- and medium rise buildings. Isyumov and Case (2000) measured torsion in the wind tunnel for three lowrise building models with different aspect ratios (length/width $=1,2$, and 3 ) in open terrain exposure. Tamura et al. (2001) examined correlation of torsion with along-wind and across-wind forces for rectangular low-rise buildings tested in simulated open and urban terrain exposures. Tamura et al. (2008) and Keast et al. (2012) studied wind load combinations including torsion for medium-rise buildings. The first study showed the importance of the wind load combinations on the peak normal stress generated in the building columns. Based on testing of limited number of building models, the latter study concluded that for rectangular buildings the peak overall torsion occurs simultaneously with $30-40 \%$ of the peak overall drag force. Additional experimental results for testing different building configurations are still required to confirm and generalize these results.

Therefore, an experimental wind tunnel study was undertaken to examine wind-induced torsion on buildings with rectangular cross-section with a typical aspect ratio of 1.6 in simulated open terrain

exposure. Furthermore, the experimental results were compared with ASCE 7 (2010) wind-induced shear force and torsion provisions.

\section{EXPERIMENTAL PROCEDURE}

The experiments were carried out in the boundary layer wind tunnel of Concordia University. The working section of the tunnel is approximately $12.2 \mathrm{~m}$ length $\times 1.80 \mathrm{~m}$ wide. Its height is adjustable and ranges between 1.4 and $1.8 \mathrm{~m}$ to maintain negligible pressure gradient along the test section. An open-country exposure was simulated in the wind tunnel. The approach flow profiles of mean wind velocity and turbulence intensity were measured using a 4-hole Cobra probe (TFI) for the simulated terrain exposure. The wind velocity at free stream was $13.6 \mathrm{~m} / \mathrm{s}$. The power law index $\alpha$ of the mean wind velocity profile was set at $\alpha=0.15$. 
All measurements were synchronized with a sampling rate of $300 \mathrm{~Hz}$ on each channel for a period of $27 \mathrm{sec}$ (i.e. about one hour in full scale). The peak shear and torsional coefficients were considered as the average of the maximum ten values picked up from a 1-hr full-scale equivalent time history of the respective signal. Also, the corresponding shear and torsion were evaluated as the average of ten values corresponding to the ten peaks.

The 1:400 building model was equipped by 146 pressure taps on its side walls - see Figure 2. Model dimensions and the tested building heights are given in Table 1. In this study, all tested buildings were assumed to be structurally rigid. Figure 3 shows a schematic representation of external pressure distributions on building envelope at a certain instant, the exerted shear forces, $F_{X}$ and $F_{Y}$, along the two orthogonal axes of the buildings, as well as torsional moment, $\mathrm{M}_{\mathrm{T}}$, at the geometric centre of the building. Pressure measurements are scanned simultaneously. All these forces are normalized with respect to the dynamic wind pressure at the roof height as follows:

$\mathrm{C}_{\mathrm{vx}}=\frac{\mathrm{F}_{\mathrm{x}}}{\mathrm{q}_{\mathrm{h}} \mathrm{Bh}} \quad \mathrm{C}_{\mathrm{vy}}=\frac{\mathrm{F}_{\mathrm{Y}}}{\mathrm{q}_{\mathrm{h}} \mathrm{Bh}} \quad \mathrm{C}_{\mathrm{v}}=\frac{\mathrm{V}}{\mathrm{q}_{\mathrm{h}} \mathrm{Bh}}$

where $\mathrm{V}=$ resultant force, $q_{\mathrm{h}}=$ dynamic wind pressure at roof height $\left(\mathrm{kN} / \mathrm{m}^{2}\right), \mathrm{B}=$ smallest horizontal building dimension $(\mathrm{m})$, and $\mathrm{h}=$ mean roof building height $(\mathrm{m})$. The torsional coefficient, $\mathrm{C}_{\mathrm{T}}$, and equivalent eccentricity, e, are evaluated based on:

$\mathrm{C}_{\mathrm{T}}=\frac{\mathrm{M}_{\mathrm{T}}}{\mathrm{q}_{\mathrm{h}} \mathrm{BhL}} \quad \mathrm{e}(\%)=\frac{\mathrm{M}_{\mathrm{T}}}{\mathrm{LV}} \times 100$

where $\mathrm{L}=$ longest horizontal building dimension.

\section{RESULTS AND COMPARISONS WITH ASCE 7 (2010)}

By definition, the distribution and the magnitude of wind forces on building envelope are linked to the magnitude of torsional moment acting on the building. Therefore, based on the wind tunnel measurements, two load cases are presented; Case $\mathrm{A}$ shows maximum torsion $\left(\mathrm{C}_{\mathrm{T}}\right.$ Max. $)$ with 
corresponding shear $\left(\mathrm{C}_{\mathrm{V}}\right.$ Corr. $)$, while Case $\mathrm{B}$ shows maximum shear $\left(\mathrm{C}_{\mathrm{V} \text { Max. }}\right)$ with corresponding torsion $\left(\mathrm{C}_{\mathrm{T} \text { Corr. }}\right)$. The results of the wind tunnel tests (Case A and Case $\mathrm{B}$ ) for the tested building heights were compared to the values for base shear force and torsional moment evaluated using ASCE 7 (2010).

The three analytical procedures stated in ASCE 7 (2010) to evaluate wind loads were applied for this comparison. The envelope method appropriate for low-rise buildings (with conditions that $\mathrm{h}<18 \mathrm{~m}$ and $h<B$ ) where $h$ and $B$ are the mean roof height and the smallest horizontal dimension, respectively, was used. Also, the ASCE's figure 28.4-1 is used to get the external pressure coefficients $\left(G C_{p f}\right)$. The basic (transverse) and torsional load cases presented in figure 28.4-1 of ASCE 7 (2010) are used to estimate the maximum torsional moment and the maximum base shear. In ASCE 7 (2010), directional methods, Part I proposed for all building heights and Part II recommended for buildings up to $48.8 \mathrm{~m}$ height, are also considered in this comparison. External pressure coefficients were collected from figure 27.4-1. Pressure coefficients are provided in table 27.6-1 for buildings with height up to 48.8 m. For consistency, ASCE 7 (2010) calculations were carried out considering the open terrain exposure $\mathrm{C}$.

Figure 4 summarizes the results for Case A. Peak torsional coefficients $\left(\mathrm{C}_{\mathrm{T}}\right.$ Max. $)$, corresponding shear $\left(\mathrm{C}_{\mathrm{v}}\right.$ corr. $)$, and equivalent eccentricity (e (\%)) are evaluated using the wind tunnel study and ASCE 7 (2010). For low-rise buildings, the envelope method in ASCE 7 (2010) shows relatively good agreement with the measured $\mathrm{C}_{\mathrm{T} \text { Max., }}$ whereas the measurements show that the equivalent eccentricity e (\%) could be reduced from about $18 \%$ to be $15 \%$. The directional methods (Part I and II) necessitate equivalent eccentricity $15 \%$ which seems to be in relatively good agreement with the wind tunnel results $(\approx 13 \%)$. At the same time, it can be seen from the figure that the directional methods apply significantly higher $\mathrm{C}_{\mathrm{v}}$ corr. Consequently, the $\mathrm{C}_{\mathrm{T}}$ max. evaluated using these two methods is significantly greater than the measured wind tunnel torsion. For instance, the Directional I method applies torsion that is almost three times higher than the values measured in the wind tunnel for the 50 
$\mathrm{m}$ high building. As such, reducing the $\mathrm{C}_{\mathrm{V}}$ corr. would improve the directional methods' predictions for torsion on rectangular low- and medium-rise buildings with aspect ratio (L/B) 1.6. Hence, it could be suggested for the torsion load case of the directional methods in ASCE 7 (2010) to apply 50\% instead of $75 \%$ of the full wind load with the same eccentricity, i.e. $15 \%$ of the facing building horizontal dimension.

A comparison between the shear load case predicted using the provisions of the ASCE 7 (2010) wind standard, and that measured in the wind tunnel, is presented in Figure 5. The shear load case, Case B, the maximum shear $\left(\mathrm{C}_{\mathrm{v} \text { Max. }}\right)$, corresponding torsion $\left(\mathrm{C}_{\mathrm{T} \text { Max. }}\right)$ and equivalent eccentricity $(\mathrm{e}(\%))$ clearly indicates that the envelope method for low-rise buildings in ASCE 7 (2010) is indeed capable of predicting $\mathrm{C}_{\mathrm{v} \text { Max. }}$ and $\mathrm{C}_{\mathrm{T} \text { corr. }}$ on low-rise buildings. Although, the directional methods (Part I and II) of ASCE 7 (2010) provisions significantly overestimate the shear forces on the studied buildings, it has to be noted that the wind loads introduced in these shear load cases are uniformly distributed on building face. Thus, the directional methods do not consider the corresponding torsion. For instance, the directional method part II applies shear force that is more than two times higher than the measured in the wind tunnel for the $50 \mathrm{~m}$ high building. Although this high shear force (without torsion) may be conservative in the case of designing buildings that have their main structural elements placed at the exterior building perimeter, it may not be safe for those buildings that have their main structural elements located near to the core, i.e. buildings that are sensitive to torsion or unbalanced wind loads. Therefore, designing the building for equivalent shear force similar to that measured in the wind tunnel along with the measured corresponding torsion is seen to be more representative of the actual wind loads acting on low- and medium-rise buildings with aspect ratio $(\mathrm{L} / \mathrm{B})=1.6$.

\section{CONCLUSIONS}

Wind-induced torsion and shear were measured in the wind tunnel for four flat-roof buildings having horizontal aspect ratio equal to 1.6 and different full-scale equivalent heights ranging from $6 \mathrm{~m}$ to 50 
m. The analysis of experimental results and comparisons with the American standard ASCE 7 (2010) shows that, for low-rise buildings, the envelope method in ASCE 7 (2010) shows relatively good agreement with the measured torsion and shear force; whereas for medium-rise buildings, wind load provisions in ASCE 7 (2010) overestimate torsion and shear force.

\section{REFERENCES}

ASCE 7 (2010) "Minimum design loads for buildings and other structures." Structural Engineering Institute of ASCE, Reston, Va.

CEN. (2005) "Eurocode 1: Actions on Structures - Part 1-4: General actions - Wind actions" $\operatorname{Pr}$ EN 1991-1-4, Brussels

Elsharawy, M., Stathopoulos, T., and Galal, K. (2012) "Wind-Induced torsional loads on low buildings." Journal of Wind Engineering and Industrial Aerodynamics, Vol. 104-106, 40-48

Isyumov, N., and Case, P. C. (2000) "Wind-Induced torsional loads and responses of buildings." Proceedings of the Structures Congress, Sponsored by ASCE/SEI, Philadelphia, May

Keast, D.C., Barbagallo, A., Wood, G.S. (2012) "Correlation of wind load combinations including torsion on medium-rise buildings." Wind and Structures, An International Journal, 15(5), 423-439

NBCC (2010) “User's Guide - NBC 2010, Structural Commentaries (part 4).” Issued by the Canadian Commission on Buildings and Fire Codes, National Research Council of Canada

Standards Australia (2011). "Structural Design Actions Part2 Wind Actions." AS/NZS 1170.2-2011, Standards Australia

Tamura, Y., Kikuchi, H., Hibi, K. (2001) "Extreme wind pressure distributions on low- and middlerise building models." Journal of Wind Engineering and Industrial Aerodynamics, 89 (14-15), $1635-1646$ 
Tamura, Y., Kikuchi, H., Hibi, K. (2008) "Peak normal stresses and effects of wind direction on wind load combinations for medium-rise buildings" Journal of Wind Engineering and Industrial Aerodynamics, 96 (6-7), 1043-1057 


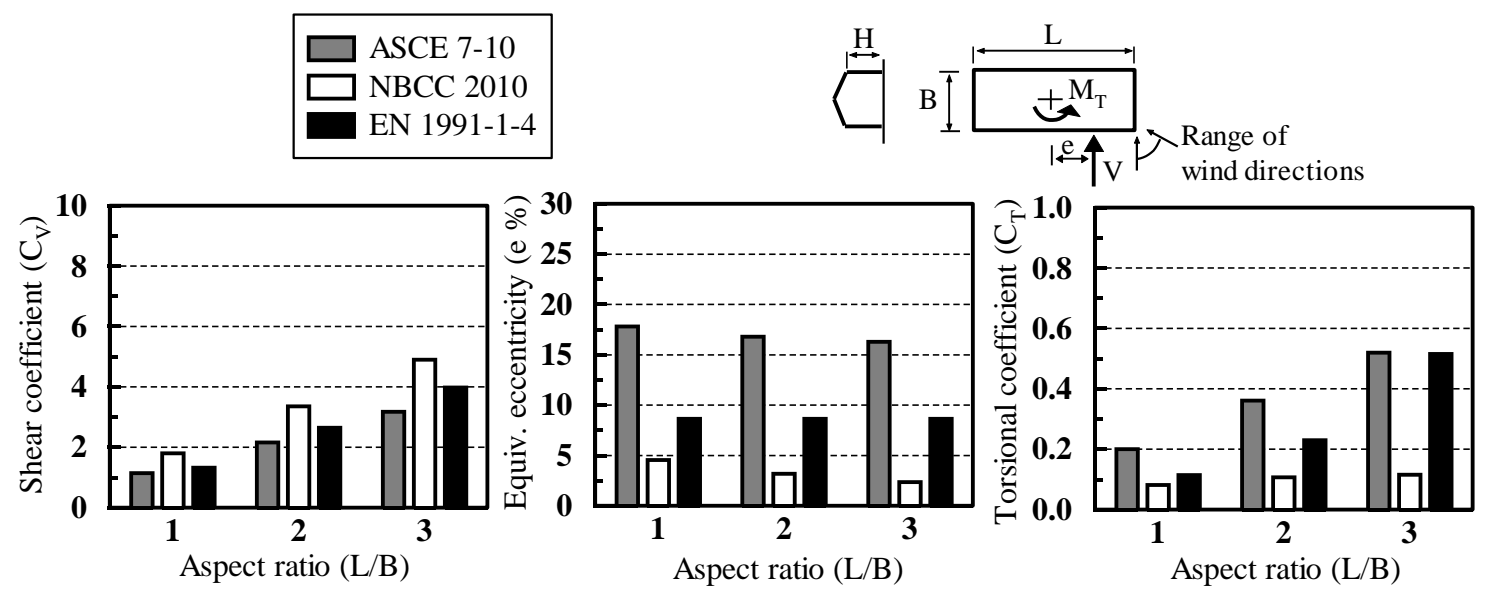

Fig. 1 Comparison for the torsional loads evaluated using ASCE 7 (2010), NBCC (2010), and EN 1991-1-4 for three low rise buildings (Elsharawy et al. 2012) 

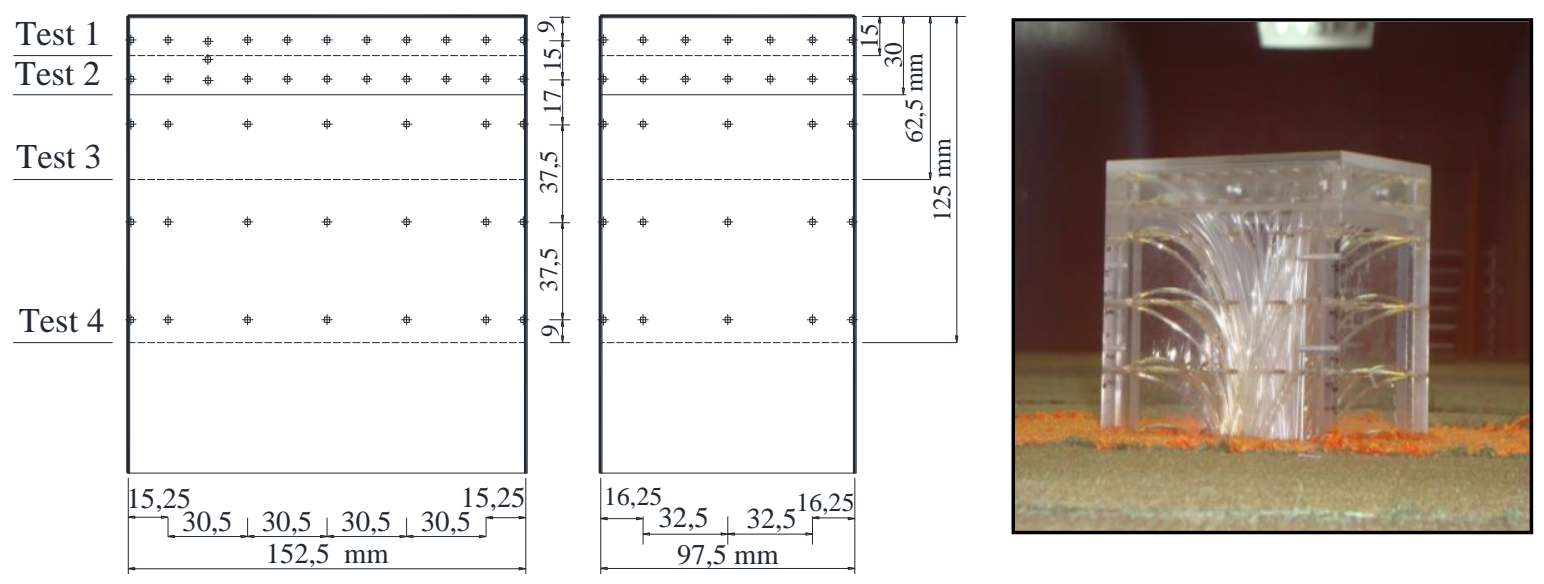

Fig. 2 Building model and pressure tap location 


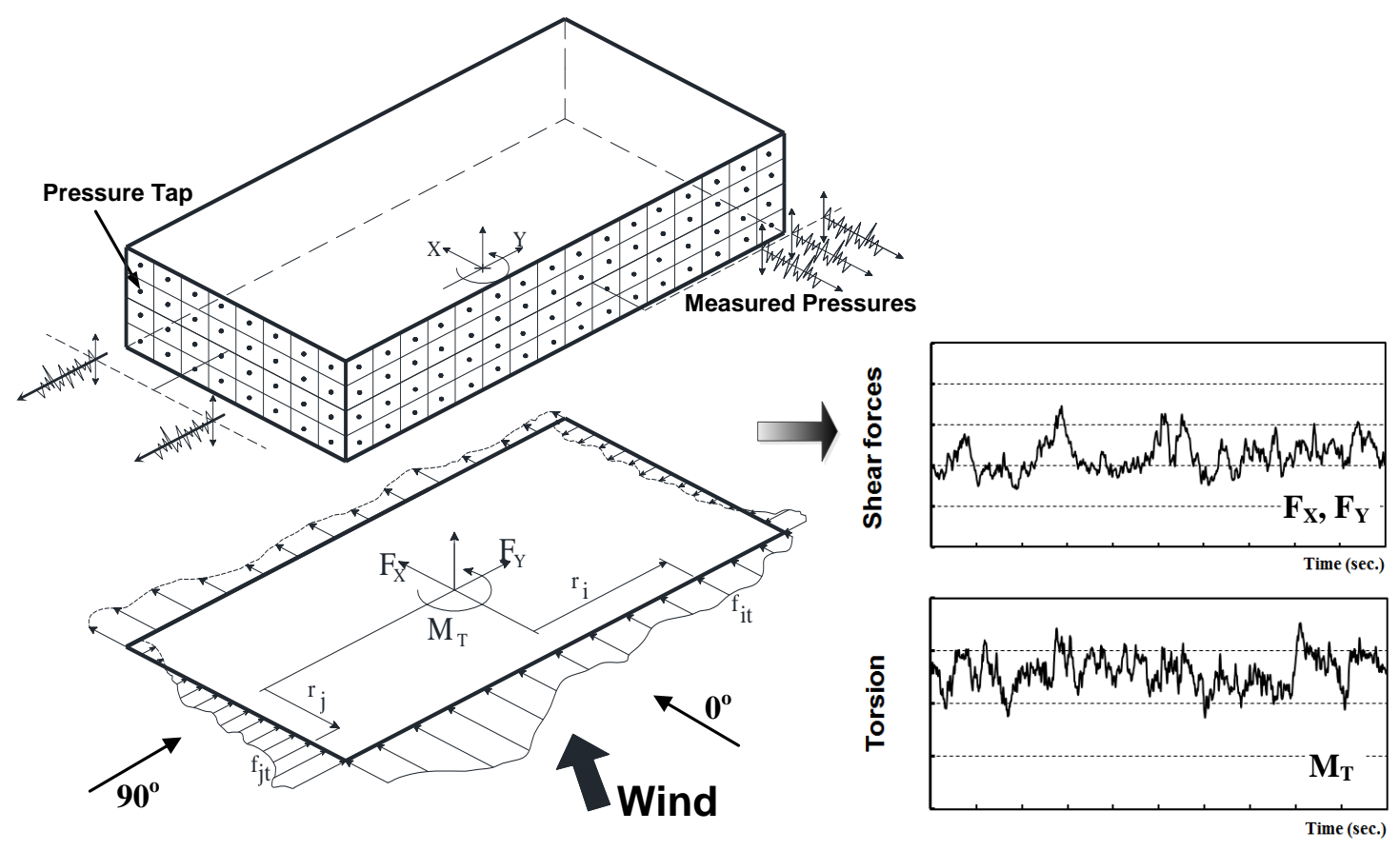

Fig.3 Measurement procedure for horizontal wind forces, $\mathrm{F}_{\mathrm{X}}$ and $\mathrm{F}_{\mathrm{Y}}$, and torsional moment, $\mathrm{M}_{\mathrm{T}}$ 

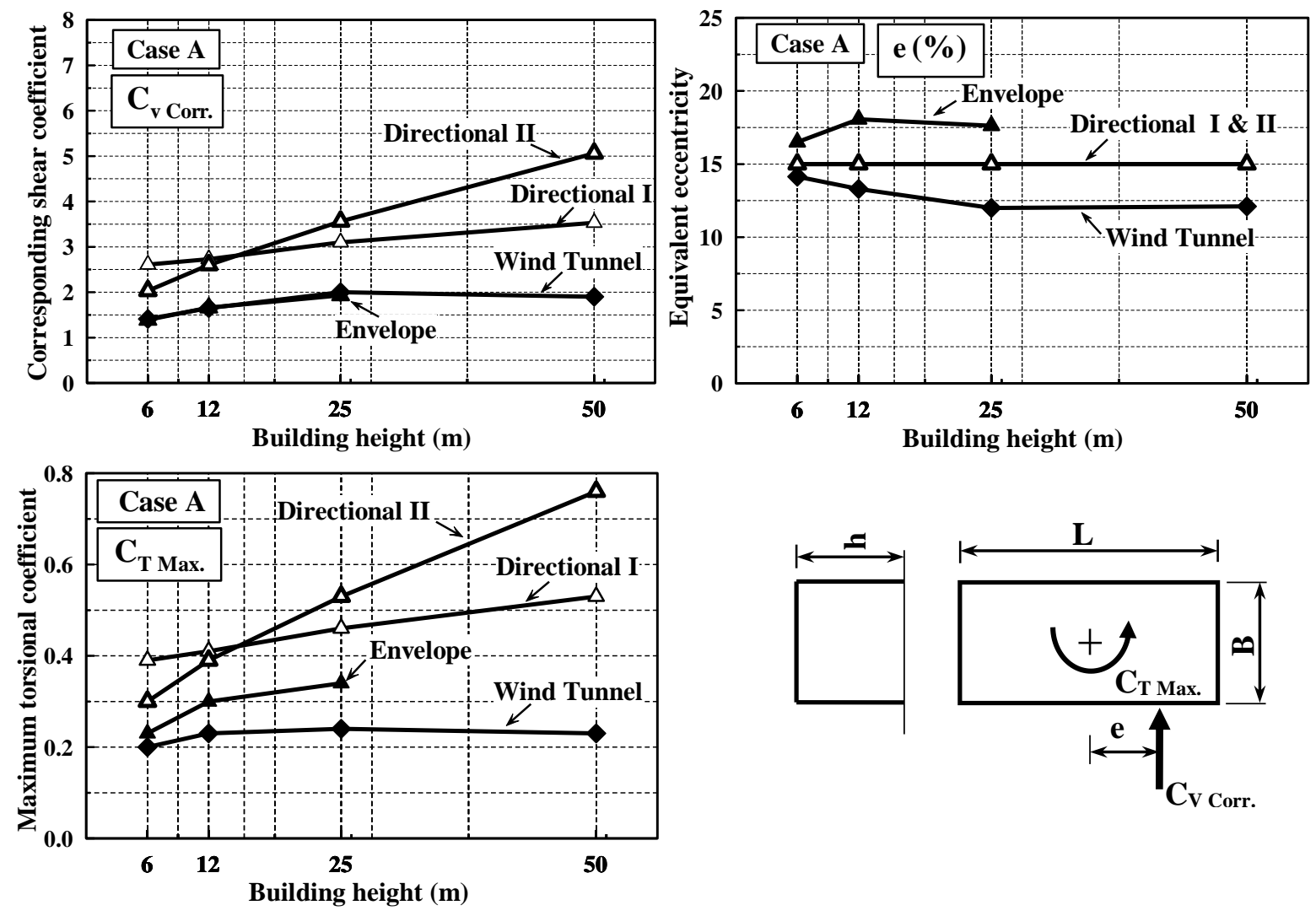

Fig. 4 Comparison of torsional load case evaluated using ASCE 7-10 and wind tunnel results (Case A: maximum torsion and corresponding shear) 

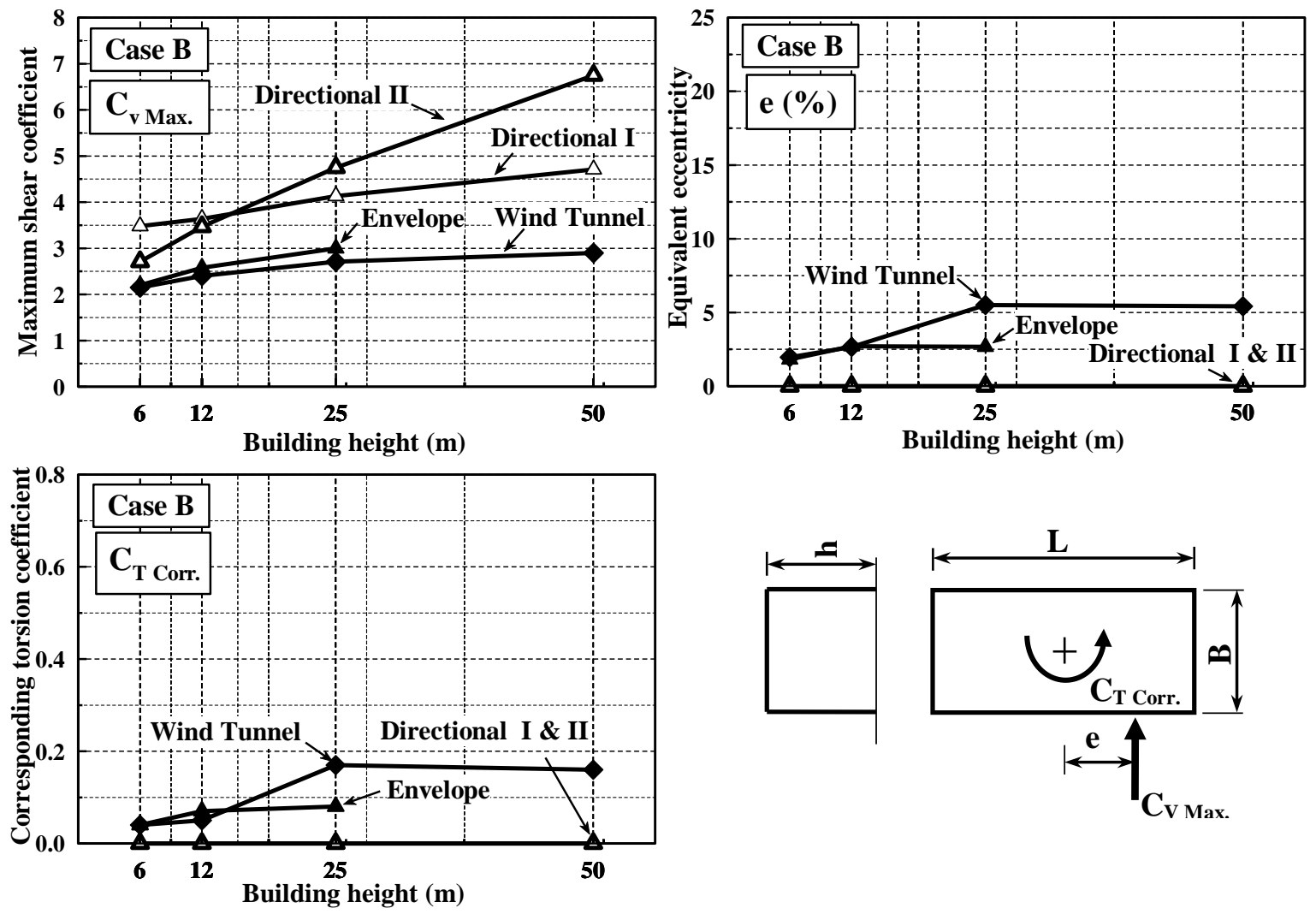

Fig. 5 Comparison of shear load case evaluated using ASCE 7-10 and wind tunnel results (Case B: maximum shear and corresponding torsion) 
Table 1. Model dimensions and building heights tested

\begin{tabular}{lcc}
\hline \multirow{2}{*}{ Building } & \multicolumn{2}{c}{ Dimensions } \\
& Scaled $(1: 400, \mathrm{~mm})$ & Actual $(\mathrm{m})$ \\
\hline Width (B) & 97.5 & 39 \\
Length (L) & 152.5 & 61 \\
Tested heights (h) & $15,30,62.5,125$ & $6,12,25,50$ \\
\hline
\end{tabular}

